\title{
SEXUALIDADE FEMININA - A LINGUAGEM DO CORPO
}

\author{
Maria do Amparo Rocha Caridade ${ }^{1}$
}

FEMALE SEXUALITY BODY LANGUAGE.

\begin{abstract}
Resumo: Tomando por base alguns autores, procede-se a uma série de reflexões críticas, sobre as influências do meio ambiente e da cultura no desenvolvimento da sexualidade feminina. Iniciando-se com a clássica citação de Simone de Beauvoir de que "não se nasce mulher, torna-se mulher", pontua-se uma série de crenças, atitudes, valores e comportamentos, que serão as constantes vinculadas ao desenvolvimento da feminilidade.
\end{abstract}

Palavras-chave: Sexualidade feminina. Influências sociais e culturais. Gênero.

Abstract: Based in some authors, we proceded a series of critical reflections on the influences of the environment and the culture in the development of female sexuality. Starting with the classic quote from Simone de Beauvoir that "not born woman becomes woman", we points out a series of beliefs, attitudes, values and behaviors, which will be linked to the constant development of femininity.

Keywords: Female sexuality. Social and cultural influences. Gender.

"Não se nasce mulher, torna-se mulher,"anuncia Simone de Beauvoir ao observá-la na história. Diria que, também não se nasce com o corpo erógeno pronto, mas em potencial. Ele se estrutura no contexto interativo de atitudes e linguagem que cercam o indivíduo, e que vão sendo internalizadas no curso de cada história É arqueológica essa construção. Podemos pensar portanto, num "corpo processo", que se constrói e se revela continuamente em seu erotismo, em suas linguagens. Não há corpo de história finda, mas corpo que se faz.

Como se plasma em nossas histórias esse corpo erógeno, sua linguagem e sua expressão adulta? E fora de dúvida que, desde os primórdios do existir humano, somos abertos e sensíveis ao que nos cerca. A ruptura da simbiose uterina e a liberação do grito primal, foram aventuras necessárias, condições imprescindíveis a partir das quais nos ligamos ao meio externo. A partir de então, os canais sensoriais vão registrando, inscrevendo em nossa psique, as pegadas da vida, os gestos, dores e emoções do cotidiano de cada um. Palavras, atitudes, expressões, sensações, emoções, tudo vai sendo captado, armazenado, introjetado pelo bebê, que, como uma esponja, absorve tudo o que lhe toca a superfície. A sexualidade humana se plasma em meio a estas inscrições que o corpo vai armazenando fielmente, como produto da

\footnotetext{
Artigo publicado na Revista Brasileira de Sexualidade Humana, 5(2), 1994, p. 142-46. São Paulo: Iglu, 1994.

${ }^{1}$ Psicóloga. Mestre em Antropologia da Universidade Católica de Pernambuco.
} 
diversidade de gestos postos ao existir humano. As inscrições grudam ao corpo, de modo inconsciente, mas em cada célula, em cada modus vivendi. Deixamos de ser mera possibilidade, e resultamos numa história mnêmica singular.

Françoise Dolto (1989) analisa como se dá a estruturação do erotismo da menina, e o faz numa perspectiva desenvolvimentista, histórica e construtivista. Desde os primeiros momentos, a acolhida ou desapontamento dos pais face à chegada do bebê menina, a felicidade ou tristeza manifestada por ela ser uma mulher, a presteza ou hesitação com que lhe conferem um nome, se este nome é feminino ou neutro, os comentários acerca de sua aparência, saúde ou beleza, tudo referencia já, se ela está sendo benvinda à vida, se ela será aceita e amada como mulher. As atitudes dos pais, as coisas ditas consciente ou inconscientemente, são elementos com os quais o bebê menina vai construindo uma imagem de si, vai se narcisando ou se rejeitando em seu sexo e sua pessoa. O sexo biológico não lhe define ser mulher. A feminilidade vai se construindo em meio à linguagem circundante, em meio às expressões de aprovação, de consideração e de alegria por seu sexo. Isto é transmitido pelos adultos, mas sobretudo pela mãe quando expressa ou não o orgulho de ser mulher. E nesse espelho mãe, que a menina em desenvolvimento vai conferir, legitimar e reconhecer a dor e a delícia de ser mulher.

O desenvolvimento da motricidade proporciona a descoberta do corpo, e toma-se uma oportunidade progressiva para se fazer a nomeação de cada uma de suas partes, inclusive de seu sexo. Oxalá não se use para isto, termos depreciativos.

Eufemismos, apelidos, podem ser usados, como uma espécie de sobrenome do sexo, desde que não se omita o verdadeiro nome. Que não haja pudores de se nomear a vulva, o clitóris, a vagina, etc. "O que não tem nome não é nada”, diz F. Dolto (1989). Se nada é dito acerca do sexo, isso por si só gera uma tensão, que pode tornar compulsiva a manipulação dos genitais, como uma tentativa de desvendar o mistério do não dito, uma espécie de busca inconsciente de confirmação destas partes silenciadas. O papel do adulto é confirmar que ela é uma menina em seu sexo, que isso é bom, e que as diversas partes de seu corpo que ela está tocando e reconhecendo, lhe dão prazer. Isso legitima e registra como positivo, o que ela experimenta em seu corpo. Aí as dimensões do permitido/proibido vão ser fundamentais ao desenvolvimento de uma sensualidade sadia Quando ela descobre a diferença sexual em relação ao menino é preciso dizer-lhe que é nessa diferença que ela é uma menina, que ela é como a mãe, que é bonito ser mulher, que ter vulva de menina é tão importante como ter pênis de menino. Isso lhe alicercará nela a percepção de que as diferenças constituem a beleza de 
sermos homens e mulheres, sem referência a qualquer hierarquia entre os sexos.

A curiosidade natural acerca da intimidade dos pais, será elemento de valorização do relacionamento amoroso, se lhe forem respondidas com transparência as questões daí provenientes. E hora de desvendar-lhe o mistério que envolve a cena primordial que dá origem à vida. A chegada da menarca, se referida como promoção, sinal de feminilidade e prontidão para a procriação, e não como doença ou desconforto, também será elemento de valoração natural do ser mulher. Se ela se narcisa com as características de seu sexo, a libido genital é despertada em relação ao falo e ao desejo de futura penetração. Cabem aí as informações sobre o mecanismo da ereção peniana, que lhe servirão inclusive de referencial acercado desejo sexual despertado no macho. Em todo esse processo, a atuação da mãe pode construir na filha, o sentido estético-ético de sua sexualidade, num contínuo refletir, espelhar a identidade entre o corpo e a feminilidade de ambas. Tendo informações adequadas, a menina desenvolverá capacidade de pensar por si, e não apenas guiar-se pela mídia que, em geral, valoriza mais o prazer físico que a simbolização dos valores femininos. Adultos receiam fornecer estas informações, supondo que elas acordem precocemente o desejo. É um equívoco a reparar, porque, é o desejo amordaçado, não legitimado, que perturba, que perverte. A informação adequada torna natural a condição sexual, tranquiliza e torna a pessoa responsável em seu sexo.

O contexto familiar é o núcleo primeiro onde se plasma a sexualidade da mulher. Mas a cultura faz aí suas investidas e a sociedade termina por se refletirem nosso modo de ser. Em seu livro Tabu do Corpo, José Carlos Rodrigues diz que: “...o corpo é pouco mais que uma massa de mod- elagem à qual a sociedade imprime formas segundo suas próprias disposições; formas nas quais a sociedade projeta a fisionomia do seu próprio espírito”. (1983) Importa constatar o quanto isso se reflete em nossa sexualidade. Mais explicitamente ele diz: "Em cada sociedade poder-se-ia levantar o inventário dessas impressões mensagens e descobrir-lhes o código: bom caminho para se demonstrar na superfície dos corpos, as profundezas da vida social." (idem). Através de ritos, códigos e leis, a sociedade proporciona cicatrizes de identidade. Cicatrizes que marcam, que lembram, que recordam o social imposto ao corpo. Verdiglione (s/d) acha que todo esse trabalho ideológico, é um processo de laceração, razão porque é preciso “...por-se à escuta dos passos perdidos, por-se à procura das pistas quase desapareci-das que percorrem as mil veredas que atravessam os corpos."

E com esse corpo processo, corpo história, que vivemos a sexualidade. A cultura ocidental desenvolveu um conceito instrumentalista do corpo, que, reforçada pela visão dualista, 
norteou toda uma negação do prazer em favor da produção. Particularmente, o corpo da mulher foi tomado produtivo. Apropriado pelo social para fins meramente procriativos, foi reduzido, submetido e colocado a serviço da família. O surgimento dos contraceptivos ajudou a revolucionar essa postura, e as mulheres começaram a se reapropriar do corpo. Mas ficaram sequelas da concepção utilitarista e inferiorizante do corpo e da mulher. Sequelas que pesam ainda sobre o prazer e a sexualidade da mulher atual. Sequelas-mensagens, linguagem de corpos impedidos. Apesar das mudanças já ocorridas, grande contingente de mulheres, ainda tem seu corpo como um estrangeiro, ou mesmo como um inimigo. Receiam o prazer e desconhecem suas sensações, ignoram a força e a importância da própria sexualidade. Essas sequelas se estampam quase sempre por sintomas que são verdadeiras mensagens, denúncias de pré-história do corpo feminino minimizado, negado em seu direito à sexualidade. Desinteresses sexuais, inibições do desejo, falta de excitação, dispareunias e vaginismos, podem estar denunciando essas histórias, podem evidenciar áreas do corpo como carceres de prazer. A construção desses sintomas foi dinamicamente acontecendo através de inscrições historicizadas, peculiares ao processo de cada pessoa. O sintoma pode ser o signo de uma linguagem que não foi decodificada, inconsciente, portanto, linguagem de corpo doído.

Quando há uma trajetória positiva nas experiências relativas ao sexo, são possíveis significativas expressões do prazer. O corpo é sempre uma surpresa. Creio que o corpo feminino é tão potencialmente capaz de prazer, que precisou de uma cultura negadora e impedidora disso. Miticamente foi preciso deter Eva e Lilith em suas ousadias. A mulher liberta, que tem a sexualidade e o prazer legitimados, não receia a si própria, não teme a aventura da sensação que cada parte do corpo lhe proporcionar. É sua peculiaridade ser erógena de corpo inteiro, e se for tocada com sabedoria, revela uma gama imensa de sensações prazerosas. Tratase de um prazer globalizaste, não apenas genitália, mas pele total, sensação mesclada de sonho, poesia e metáfora. Corpo de mulher é assim, meio matéria, meio espírito. Atingida só no corpo matéria, não é alcançada em sua potencialidade. Frustra-se e frustra os homens que não a percebem como tal. Acho que o equívoco atual na busca feminina da sexualidade, é talvez uma ânsia da sensação do corpo pelo corpo, tentativa de certo, de resgate do que foi tanto tempo negado.

O feminino está para além da mera sensação. Lacan expressa isso, quando considera que a feminilidade se especifica por um desdobramento do gozo que não se reduz à oposição vagina-clitóris. Daí distingue o gozo do prazer. O gozo é gozo do SER, diz ele, e suporta o "eu sou”. Um gozo quase inacessível, porque não corresponde a desejo algum; um gozo que resiste a toda apreensão e raciocínio. Assim ele situa a sexualidade feminina num mais além 
da função fálica Comentando Lacan, Serge André (1987) diz: "Em seu gozo efetivo, ou pelo menos na parte de seu gozo que ultrapassa a referência fálica, uma mulher só pode querer para parceiro, um ser que se situe ele mesmo para além da lei do falo”. Diria que a mulher goza em seu corpo e para além dele. Por isso ela evoca uma linguagem que nem todos os

homens entendem. Apenas aqueles que se superam em sua genitalidade, que vão além da mecânica dos corpos e do prazer que daí resulta. Roland Barthes dá idéia de como isso se processa: "Além da cópula há esse outro enlace que é o abraço imóvel. Estamos encantados, enfeitiçados. Estamos no sono sem dormir.” (1989).

\section{Referências bibliográficas}

ANDRÉ, S. O Que Quer uma Mulher? Rio Janeiro: Jorge Zahar Editor, 1987.

BARTHES, R. Fragmentos de um Discurso Amoroso. Rio de Janeiro: Francisco Alves, 1989.

DOLTO, F. Sexualidade Feminina. São Paulo: Martins Fontes, 1989.

RODRIGUES, J. C. Tabu do Corpo. Rio de Janeiro: Achiamé, 1983.

VERDIGLIONE, A. Sexualidade e Poder. Lisboa: Edições 70, s.d. 